\title{
RESIDENTIAL BUILDINGS BY GIUSEPPE TERRAGNI IN COMO: PROPOSALS FOR INTEGRATION BETWEEN RESEARCH, COMMUNICATION AND VALORISATION OF HERITAGE
}

\author{
M. Casanova ${ }^{1}$, A. Greppi ${ }^{1}$ \\ ${ }^{1}$ Department of Architecture and Urban Studies, Polytechnic of Milan, via Bonardi 3, 20133 Milano, Italy (anna.greppi, \\ marta.casanova)@polimi.it
}

KEY WORDS: Communication, Enhancement, Architectural Heritage, Preservation, Virtual tour

\begin{abstract}
:
This essay presents a proposal concerning the residential buildings of Giuseppe Terragni in the urban area of Como, based on the research activity which has been ongoing in the last few years and the related experiences which have been elaborated up to now to manage, represent and communicate the studies carried out. A new method of integration between research, communication and enhancement is presented with the aim to obtain a synthetic and immersive representation. Two case studies, in particular, are presented: the building for apartments Novocomum and "Case Popolari" in Via Anzani. The paper describes the methodology used, and its purpose, to create a virtual tour of the atrium of Novocomum and common areas of Case Popolari which allows the user to visit the spaces moving inside high definition full spherical immersive images and to consult punctual information referring to heterogeneous historical documents, providing a useful tool in order to study these architectures and contributing to the knowledge and enhancement of this architectural heritage.
\end{abstract}

\section{INTRODUCTION}

Building and developing a research, starting from the study of the author's poetics, which reflects on the ways and times of constructions, by investigating the technical and building characteristics of architectural artefacts from the original design process up to the transformation interventions that have made this heritage what we can see today, means to elaborate an articulate system, with formulation modalities strictly related to the purpose of the research, even if they are about knowledge, preservation, maintenance, communication and/or enhancement. In each case, a large quantity of heterogeneous data needs to be related to the creation of one informative system, developing appropriate methods for their systematization and better understanding, using specific representation, management and reprocessing technologies. This process takes place in different ways, often showing a dichotomy between the methodologies applied for the documentation aimed at specific processes of study and analysis of architectural artefacts, compared to those related to the same objects (Napolitano, Scherer, Glisic, 2017). Considering the different stakeholders involved in relation to the purposes expressed, during the formulation of the information system, appropriate tools are produced for a proper understanding of the contents, which in the case of communication's goal also addressed to non-experts, lead to the necessity to visualize and distribute information systems accessible to them (Bassier, Deloof, Vincke, Vergauwen, 2018). The proposal presented below, which concerns the use and development of virtual tours as means of communication and enhancement of two important buildings belonging to the architectural heritage of the twentieth century, it is now described as the possibility of reworking and synthesis of the results of researches that for their development have used

(1) An agreement between the Department of Architecture and Urban Studies of the Polytechnic of Milan and Giuseppe Terragni's archive, Carolina Di Biase's scientific manager, has allowed the access to a large archival documentation.

(2) It is important to underline that the following description, both for the selected case studies and for the research conducted, different tools for the management and representation of the information collected.

\section{CASE STUDY}

\subsection{Residential buildings by Giuseppe Terragni in Como}

If we consider the entire work of Giuseppe Terragni in Como, it is worth saying that the theme of dwelling has characterized his architectural production in the city. The research activity which has been going on in the last years and carried out in collaboration with the Archivio Terragni(1), originated in a study conducted at the same time on different residential buildings in the urban area of Como, where from 1927 to 1943 Terragni designed and built, alone or in collaboration with other architects, three buildings for multi-family dwellings, a villa and a housing complex. The possibility of dealing with the theme of housing in all its declinations and experimenting with the design of residential buildings of different categories has led to the development of recurrent themes between analogies and differences. An important aspect of the residential buildings with several apartments is related to design and construction of common areas which characterised the different architectures in their peculiarities, both in the design and construction phases, subsequently for the transformations undergone. With this contribution, we propose two different case studies chosen among the residential buildings designed by Giuseppe Terragni in Como: the Novocomum and the Case Popolari in via Anzani (2).

they will mainly focus on common parts of that residential buildings, that is a central theme related to the main proposal of this contribution. To get information about other aspects of architectural artifacts that are not considered here, please refer to the indicated bibliography. 

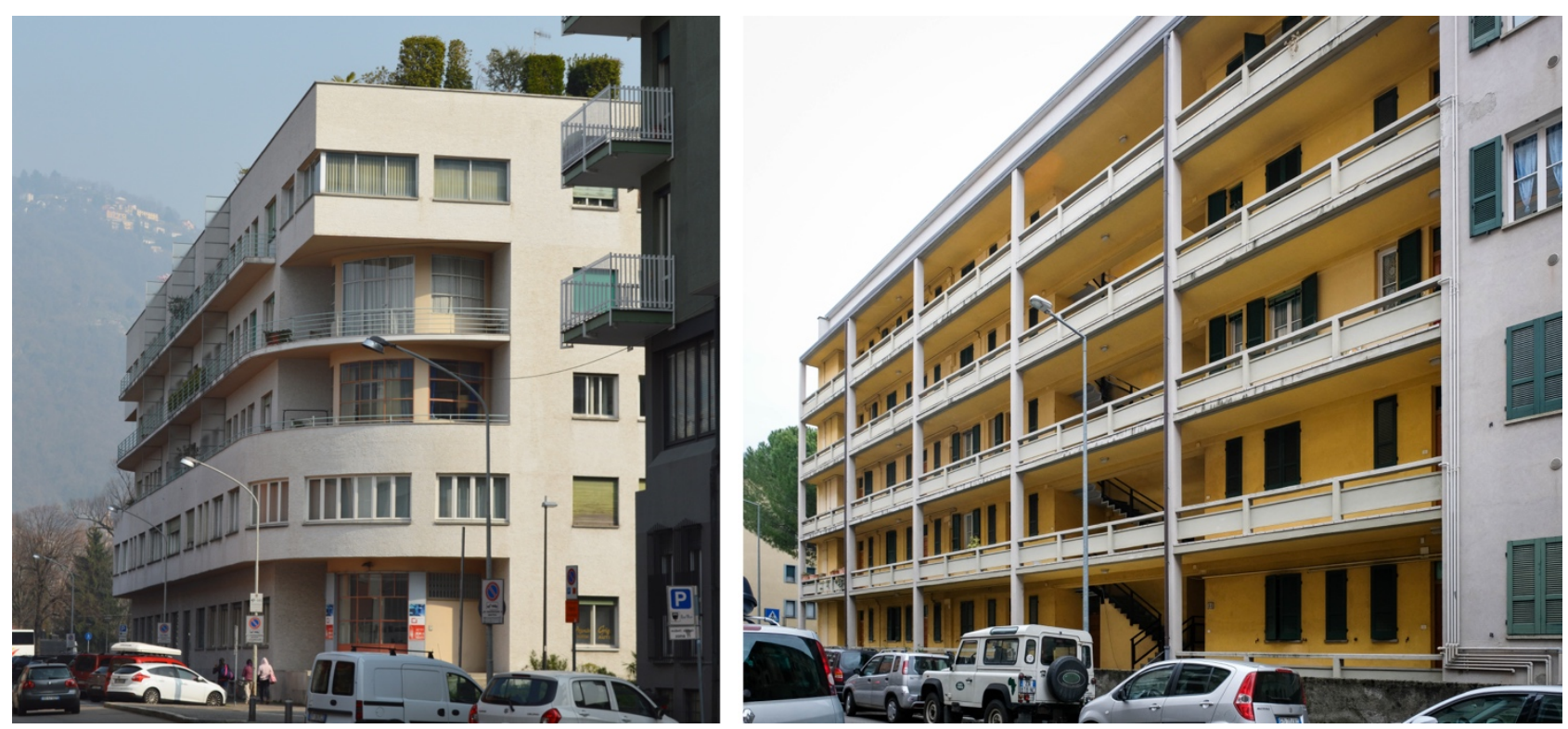

Figure 1. (left) External view of the Novocomum seen from Viale Sinigaglia, with the point of view at the northwest corner. Taken by the author in 2017. (right) External view of the Case Popolari seen from Via Anzani, with the point of view of main façade. Taken by the author in 2018.

\subsection{Novocomum}

The first case study is the Novocomum (1927-1930), a building for apartments designed and built with large experimentation and changes in progress, that in the history led to complex vicissitudes, which have given to current situation a complexity that brings the traces of the numerous transformations suffered (Di Biase, Casonato, Facchi, Greppi, 2018). Originally it was designed and built by Giuseppe Terragni as a dwelling house with different common spaces that could be used by all renters.

Among them there were the internal and external distribution spaces, the entrance hall with the related porter's lodge and the terrace overlooking the lake.

During the design elaboration, the area of the entrance hall and the main distribution system is the subject of special planning attention but also of elaboration and project's changes: very different solutions have been proposed since the two design versions of January 1928; the one selected has been furthermore modified in the drawings of October 1928 and later also in the project presented in 1929. Although it represents the last group of drawings, preserved before its realization, the one concerning the hall does not correspond to that actually built. At the end of the building work, the vicissitudes which followed led to subsequent modifications and the first known dates back to 1957 and was carried out by the architect Luigi Zuccoli; this refers to the outer and inner parts, particularly in the atrium where he changed radically the distributive and perceptive aspect.

The original entrance was originally characterized by a wide curved window made up of the minimum frames, connected with the one of the porter's lodge, with a superior luminous beam with a chromed metal frame and opal glass infill. With the intervention made by Zuccoli, everything was completely demolished and it was putted a rectilinear frame in anodized aluminium instead. The dimensions of the frames were significantly increased, the material and the partition were changed and placed in a backward position in comparison with the existing one. The entrance was

(3) When arch. Mario Di Salvo had to study the original construction about the atrium, he had only two original photographs. Before advancing his design proposal in 1988, he accurately notes the current conditions at that moment, producing a detailed survey. There is no information about any interventions changed as regards the height and consequently the proportions: the suspended ceiling was demolished. Also, the plastered finish of the walls was replaced with a coating made of Musso marble slabs. The walls of the porter's lodge were demolished in order to transform it in a minimal room with unknown function.

From 1987, the Transatlantico condominium commissioned the architect Mario di Salvo to draw up an overall project for the building, with the aim to "return to Terragni", realized by planned interventions (3). The first one concerned the return of the entrance hall, the fulcrum of the building, with a project that was drawn up from an accurate survey of the existing conditions and a detailed study of the original realisation, only with historical photographs of the construction site taken in the years. During the study, the sole preserved drawings of the luminous beam have been compared in order to investigate on how the intervention of restitution to Terragni had been successful. The operation carried out suggested that it was an accurate, meticulous and positive work, in terms of approaching the original atrium made by Terragni.

At present, the current state of the atrium preserves this last intervention, which was realised proposing again the characteristics of the original construction using non-original elements that are evidence of the building's material history.

\subsection{Case Popolari in via Anzani}

The second case study presented are Case Popolari in Via Anzani (1938-1943), designed by Giuseppe Terragni with Alberto Sartoris for the Istituto Fascista Autonomo Case Popolari in Como, chosen as an interesting case because of the different successive projects before the realization that led to important changes to the original idea of the two architects, especially regarding the common areas of the building complex.

The first project presented by Terragni and Sartoris was articulated by three buildings: two with an extensive typology and one with an intensive typology with shops and services on

carried out in the time period between 1957 and 1988, so it is assumed that the current situation registered correspond to the intervention carried out by Luigi Zuccoli. The methodology of his intervention was described in Mario Di Salvo Technical report, probably written after 9 May 1987. 
the ground floor of the high building and private gardens and vegetable gardens for the extensive type buildings. Following the first requests of modification of the project by the Ministry of Public Works, the folding windows were eliminated, the roofing of the buildings from the plain was turned into a pitch, and the lodgings at the gallery ends were extended by eliminating their corresponding part. A lot of changes followed before the approval of the final project which led to the construction of only two buildings of five and three floors without shops and services on the ground floor, with a common garden and private orchard only for the flats located on the ground floor of the lowest building.

The Case Popolari in Via Anzani have public ownership since their construction and they are now owned by ALER (Provincial Section in Como) which is in charge of the management and maintenance. The first documented work on the buildings dates back to 2001 and referred to the extraordinary maintenance of façades and roofing carried out after the report of problems by the renters. The wooden roofing structures of the two buildings were demolished and rebuilt, the windows were replaced (including shutters and entrance doors) and the sills in concrete were re-constructed; the flooring of the balconies, originally made of concrete with an engraved design of diagonally squared tiles, was waterproofed and covered with a stoneware flooring. Concerning the interiors, since 2005 the ordinary maintenance work has begun on the apartments that have been freed: these interventions are not limited to systems adaptation, but are made as global renovations with removal of plasters, floors and walls, demolition of planks and changes to the distribution of apartments (4).

\section{PREVIOUS RESEARCH EXPERIENCES}

\subsection{Recurring issues}

The researches about the proposed topic have been carried out so far (5) by different authors who found out several analogies in the themes studied. the study of these buildings, concerning both the design and building phases and the transformation phases which followed, started from the knowledge of the substantial bibliography on the theme (Sommella Grossi, 1996, Vitale, 1996) and of the archival documentation made up with both wellknown and already published iconographic documents and by the materials which were provided during the building process and which were mostly unpublished. Concerning the documentation preserved in the Terragni Archive, the research started from the identification and the study of those materials, compared to each architectural artefact and we have arranged the digitization and the subsequent cataloguing. The complexity of the process characterised all the research carried out and it was mainly determined by the definition of the relationships between the heterogeneous materials that had been collected and systematized, in order to provide to the knowledge implementation and the documentary verification and at the same time to the difficulty of managing and communicating the results of the studies carried on.

(4) In addition to the consultation of the documentation in the Archivio Civico del Comune di Como, Archivio ALER and Archivio of Soprintendenza archeologia, belle arti e paesaggio per le province di Como, Lecco, Monza e Brianza, Pavia, Sondrio e Varese some inspections were carried out on the renovation sites during 2018.

(5) A. Greppi, A. Facchi, "Il Novocomum di Giuseppe Terragni alla prova del tempo. Costruzione, trasformazioni, tutela, restauro", master's degree thesis in Architecture with qualification, Polytechnic of Milan, supervisor Carolina Di Biase, co-supervisor Camilla Casonato, a.y. 2016-2017

M. Casanova, "Edifici d'abitazione. Costruzione e trasformazioni nell 'opera di Giuseppe Terragni”, $\mathrm{PhD}$ thesis [in

\subsection{Research results' Communication through the Novocomum 3D representation}

The research carried out regarding the Novocomum case study led to the integration of all the documents collected( $\left.{ }^{6}\right)$,in continuous implementation in the development time of the studies, through the drafting of a summary chronological list, systematizing several different materials. The comparison of those data had underlined the limits of the single documents, contextualizing them in the process in progress and highlighted the numerous subsequent changes and transformations. The indepth knowledge of the vicissitudes, starting from the analysed documentation, has been further correlated to the current condition of the architectural artefact through a punctual survey, with a process based on analogies and differences, registering all the elements transformed or replaced.

The communication of the results of the research led to the choice to reconstruct the architectural object case study, investigating first of all the peculiar constructive aspects, both from the structural and finishing point of view, graphically restoring the knowledge of the entire process, from design and construction phases to all the subsequent transformations(Greppi, 2018). The informative model, that was developed with Autodesk Revit, has allowed to create a knowledge, communicative and preservation system of the architectural artefact compared to the sources acquired in the previous phases of the research. In particular, concerning the entrance hall, the 3D model was created by reconstructing all the design different versions and then the subsequent transformations, trying to produce an information system as detailed as possible which is at the same time coherent with the information level defined by the data acquired. The use of the specific program's features, which allows you to check the subsequent demolitions and reconstructions, was useful to display them graphically. The realization of this documentary product has allowed to elaborate a synthesis of the carried out research and to communicate the relative data in their details, to contribute the process of safeguard and maintenance.

\subsection{Research information management through a geo- referenced database of the Case Popolari of via Anzani}

Starting from the necessity of digitizing the documentation preserved at the Terragni Archives, an information system has been built, with the aim not to limit the archive documentation itself, but also to create a digital archival dossier for each building analysed. The archival dossier of the building is structured to allow the filing of the documentation from the design phase up to the current one and to allow cross-referencing, facilitating the critical reading of projects and transformations. The DBMS with spatial extension was designed for the cross-reading of documents stored in the different archives and, firstly, allows the extraction of a chronological register per building.

The DBMS has been linked to a GIS project in order to display documents, photographs and drawings by associating them with their position in plants, elevations and sections. The GIS has as

progress] in Preservation of Architectural Heritage, Department of Architecture and Urban Studies, Polytechnic of Milan, XXXII cycle, Head of PhD Board Maria Cristina Giambruno, supervisor Stefano F. Musso, co-supervisors Giovanna Franco, Ornella Selvafolta

(6) The documentation consulted are from the Giuseppe Terragni archive, from the municipal archive of Como, from the Soprintendenza archive (since the date that it was listed, in 12 October 1987), from the private archives of the technicians: arch. M. Di Salvo; arch. A. Albertini; arch. L. Ambrosini; arch. A. Roda; ing. F. Panzeri; F. Cani. 

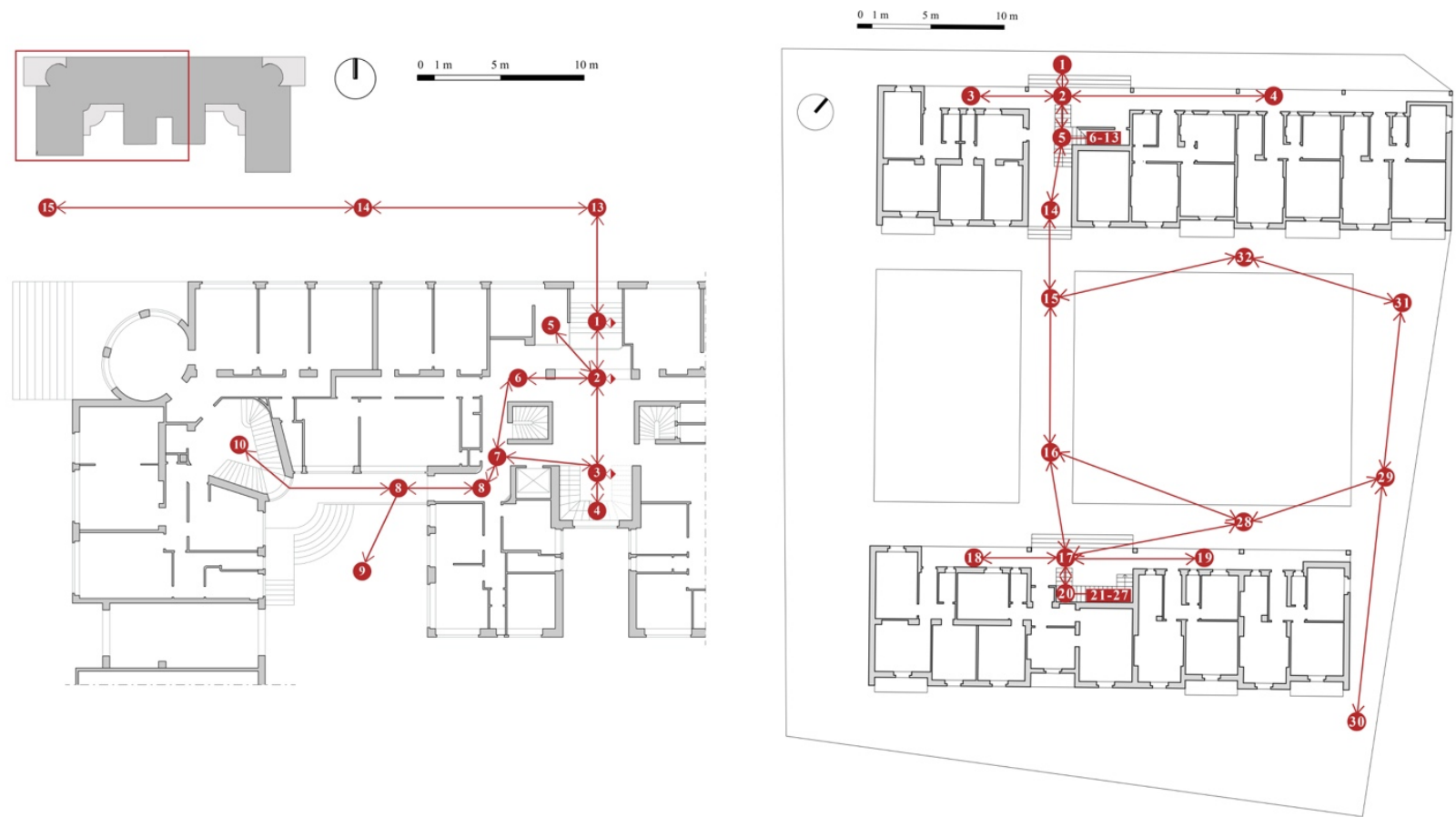

Figure 2. (left) Novocomum. Planimetric scheme of the points of acquisition of panoramic images and indication of the relationships between them (possibility to move from one to the other). The progressive number is assigned starting from the first shot that is proposed, but it is not indicative of an obligatory route. In some points, an additional symbol has been attributed which refers to the possibility of seeing the same shot both in day and evening mode. As it can be seen from the diagram itself, the shots taken in the Novocomum allow "access" to the entrance hall, to the porter's lodge and to the main staircase, to connect through the external passage in one of the two internal courtyards to one of the two internal side staircases. The first acquisition point located at the entrance stairs to the atrium, also connects to some exterior shots. (right) Case Popolari. Planimetric scheme similar to the previous one, which indicates the points of acquisition of panoramic images and indication of the relationships between them. Also in this case the progressive number is assigned starting from the first shot that is proposed, but it is not indicative of an obligatory route. As can be seen from the diagram itself, the footage taken in the Case Popolari makes it possible to "access" the distributive gallery system of both buildings, visualizing their articulation moving in the different floors. The external space included between the two buildings is equally "accessible" and it is possible to view the area behind the second building, where there are the vegetable gardens.

its graphic base the redesign, carried out in $\mathrm{CAD}$ environment, of the floor plans of each floor of the Case Popolari carried out starting from the design drawings of Giuseppe Terragni. On this graphic basis, the drawings of the different solutions and design phases were georeferenced, which can be overlapped and compared in this way. Specific layers were then created for the timely insertion of photographs, detailed drawings and documents that refer to precise elements that can be identified in the plan (Casanova, 2018). The data contained in a DBMS system can be identified in the GIS with the most appropriate geometric shape (point, line or polygon) and have a reference in the different projects (plans, elevations and sections).

This system has allowed the archiving of archival documents and information from surveys, which is essential to guarantee the integrity of information and to have a global view of the asset without losing attention to detail.

\section{PROPOSALS FOR INTEGRATION BETWEEN RESEARCH, COMMUNICATION AND VALORISATION}

The elaboration of a virtual tour is a critical operation because it creates an interactive narrative based on a re-elaboration of the knowledge system built in the previous research phases. The outcome of the virtual tour is concise and aimed at allowing the understanding of the results of previous researches based on archival and in situ investigations. In fact, the experimentation conducted showed that the virtual tour is designed by selecting the points of view and the relationships between them, the documents to be displayed, the methods and points of view. The purpose of the process is the possibility of allowing the understanding of the results of research based on archival and in situ investigations, through a communicative process that promotes knowledge and enhancement. The acquisition of panoramic images allows to photograph the current status of a place in less time than the usual photographic documentation that is produced during an inspection to document the same environment and allows you to re-visit the site through a viewer with an overall view, not fragmented.

The potentiality of use of $360^{\circ}$ images for the documentation of indoor and outdoor environments in the field of cultural heritage documenting a place during the initial phase of knowledge of a building - "initial / reconnaissance recording" (Letellier, 2011) can be used to create a virtual tour that is the basis of a communication and dissemination project that spread the results of the research itself. The use of panoramic cameras that acquires photos with HDR (High Dynamic Ranging) allows the visualizations of images with characteristics similar to those perceived by the human eye and not to lose details even in situations of non-optimal lighting with the combination of highlights and shaded areas.

\subsection{Methodology}

In this section, we propose our application for the purpose of heritage documentation, visualization and interpretation. 



Figure 3. Novocomum. Screenshot of the virtual tour, in which are visibles the hotspots of the connected documents. As described in detail in the text, the icons referring to individual documents have different shapes to indicate the various types of documents, but also different colors that recall the different design, construction and transformation phases of the building. The captions below each document contain a summary information that can be used to identify it. In this panoramic image you can see (reported from top left): on the left side the reconstruction of the demolitions and reconstructions operated with the intervention performed by the arch. Luigi Zuccoli in 1957, the perspective of the entrance of 1929 (unrealized version), the drawings of the details of the window of the atrium designed by arch. Mario Di Salvo to carry out his intervention starting from 1987; on the right side the photograph of the atrium taken after the end of construction in 1930, the photograph of the atrium taken after the intervention of Luigi Zuccoli in 1957.
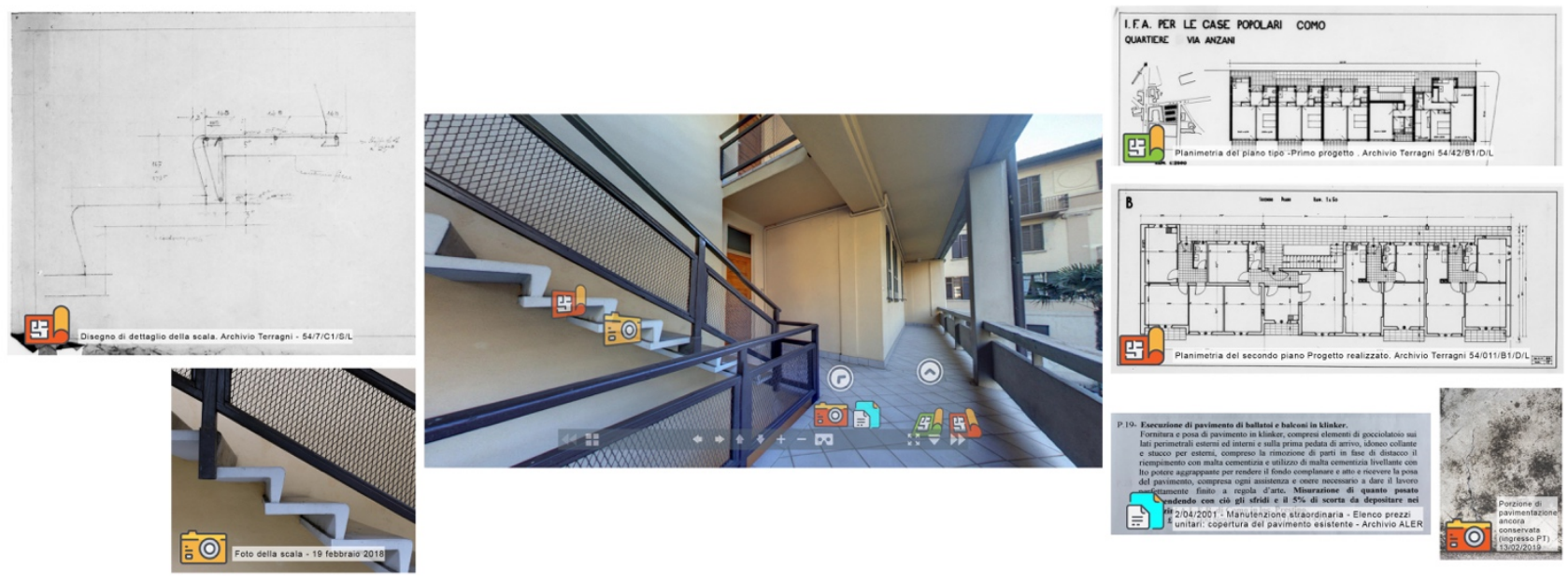

Figure 4 Case Popolari. Screenshot of the virtual tour. The features represented are similar to those described in caption 3 . In this panoramic image you can see (shown from top left): on the left side a drawing of the detail of the staircase corresponding to the construction carried out, the detail photograph of the current staircase; on the right side the first planimetric solution for the standard level of the high building (not built), the plan of the second floor of the built project.

\subsubsection{Data acquisition:}

As mentioned above, the purpose of this application is to create a simple workflow for communicating the outcomes of an archival and documentary research that allows understanding the

interactions between architectural elements, design choices, spaces and time thanks to an immersive fruition.

Panoramic images were captured with a camera, nctech iSTAR Fusion, that precisely captures full spherical immersive images and high resolution panoramic data streams. The shooting points have been chosen to allow an all-encompassing view of the spaces analyzed and create a tour that traces the normal passage of the people who use these spaces. The camera settings have been chosen according to the shooting location, selecting the internal and external options. For all internal shots, the HDR setting was used to obtain an image similar to human perception of the space, without loss of information in the areas corresponding to the highlights and shadow. The acquired images were processed within the nctech Immersive Studio software and displayed for a first verification using the viewer integrated in the program.

\subsubsection{Designing the interface:}

For the creation of the virtual tour we decided to use the krpano 1.19-pr16 (7) software with the addition of the Add Hotspot Plugin (8). The software was chosen among the various available for the possibility of inserting customized hotspots using the insertion tool without modify the html, css and js code, operations that would have required a specialist support.

The first operation consisted in the creation of the virtual tour starting from the images processed within the nctech Immersive Studio software using the Make VTour Normal droplet. The Add Hotspot plugin was inserted in the package of files created by the droplet and by opening the tour.html file in a browser it was possible to view and customize the tour. 
After connecting the views by inserting connection hotspots, and setting the startup view of each view, the hotspots relating to the photographic, textual and iconographic documentation chosen to be included in the virtual tour were inserted.

The Add Hotspot Plugin allows us to insert hotspots of different type, with customizable icons and multiple possible actions, among which the one to open an image, the one to create descriptive text boxes and the one for assign hotspots to open URL links in a new window were used.

Because of the density of the information entered, we decided to differentiate the hotspot icons inserted according to the different time phases by assigning different colours: green - unrealized projects, orange - final design and constructed building, blue modifications and subsequent transformations, yellow - current state of the building. Specific icons have been chosen to differentiate hotspots that opens photograph from those that displays a plan, a facade or a drawing of an architectural detail and those that opens a text document.

In the case of the Novocomum virtual tour, an action was also implemented that allows switching from a panoramic view taken during the day with the lighting system turned off to another panoramic view taken from the same point of the previous one, but in the evening with the lighting system turned on.

\subsubsection{Visualization:}

The visualization of the two virtual tours is now available at Archivio Terragni Association, inside the Novocomum, in a designed position to consulting the archive documentation and the virtual tour itself. The system was designed to be made available in the future on the Association's website so it can be used by a greater number of users.

The virtual tours open with the panoramic view of the entrance of the two buildings from which each user can choose which path to take during the visit and is free to consult or not the documentation that is proposed through the icons placed on the relative objects or in line with the corresponding views.

The purpose of the virtual tour is to provide an immersive and comprehensive data experience.

\subsection{Advantages and limitations}

\section{Advantages:}

Cheapness of the acquisition and reprocessing system;

High speed of data acquisition and possibility to repeat the shots in the same points at later times, recording differences in lighting;

The system allows intuitive understanding of the spaces even to those who don't have the possibility to access them.

\section{Limitations:}

It is not possible to change the points of view of the virtual tour that are chosen a priori during the acquisition of the photographs which is instead possible by navigating in a $3 \mathrm{D}$ model;

The visualization of the virtual tour, elaborated through panoramic images, proposes a point of view analogous to that of the user who visits that space, but the overall perception is less immediate, with difficulty in understanding the geometries and proportions that is better instead in the observation of a $3 \mathrm{D}$ model, especially with axonometric views;

Until now it hasn't been possible to develop the possibilities of interoperability of the three systems adopted (GIS, BIM, VT).

\section{CONCLUSIONS AND POSSIBLE FUTURE DEVELOPMENTS}

The development of the presented proposal has led to highlight the positive aspects deriving from the realization of the virtual tours described, which are prefigured as a new possibility to introduce these famous architectural artefacts in detail. The potentialities of this application allow the "access" to the interiors of the common spaces in these residential buildings, suggesting a vision that goes beyond the iconic image that has always characterized them. Furthermore, the information system of documents associated with the tour allows to show the design, construction and transformation process that has marked these architectures, allowing them to intuitively understand their current conditions. At the same time, this operation also allows non-expert users to approach the archive documentation related to case studies in a simple way.

This contribution presented a proposal that opens up to various possible developments, above all relating to the extension of the execution of this methodology to all the buildings designed by Giuseppe Terragni, with the aim of contributing to the knowledge and enhancement of his entire work, making it "accessible" even to non-experts stakeholders and to those who can't visit it physically. To pursue this goal, in the future it will also be possible to think about the differentiation of virtual tours by proposing different declinations depending on the users who visualize them, both according to individual previous knowledge (expert/non-expert users) and age (adults/children). Another aspect that could be the object of in-depth study and development in the future concerns a better interoperability between the BIM reconstructions that could be processed related to the buildings, the DBMS of all the archival data and the virtual tours formulated concerning these architectures, in order to create an easy network between one and the others, with a strong interrelationship between the different systems, that today is not still developed in all its possibility.

One of the possible developments of the research could lead to the creation of applications based on Augmented Reality to allow the use of graphical and iconographic information already implemented in the virtual tour also through in situ visits.

It still remains to explore the multiple possibilities offered by the tools of virtual and augmented reality in relation to the real architecture that should have to be known and valorized, both if they are used with a general knowledge function or with a didactic purpose.

This contribution is proposed to be a first step concerning the topic of integration between research, communication and enhancement of that specific studied heritage and it wants to provide some thoughts related to this theme that can be the basis for future research.

\section{REFERENCES}

Sommella Grossi, M., 1996. Case Popolari di via Anzani a Como. In: Ciucci, G., Giuseppe Terragni. Opera completa. Electa, Milano, $578-581$.

Vitale, D., 1996. Edificio ad appartamenti Novocomum a Como. In: Ciucci G., Giuseppe Terragni. Opera completa. Electa, Milano, 315 - 321 .

Letellier, R. 2011. Recording, Documentation and Information Management for the Conservation of Heritage Places. The Getty Conservation Institute, Los Angeles.

Bassier, M., Deloof, T., Vincke, S., Vergauwen, M., 2018. Panoramic Image Application for Cultural Heritage. In: Ioannides, M., et al. (eds), Digital Heritage. Progress in Cultural Heritage: Documentation, Preservation, and Protection. EuroMed 2018. Lecture Notes in Computer Science, vol. 11196. Springer, Cham.

Casanova, M., 2018. Un dossier archivistico per la conoscenza di Casa Pedraglio. In: ReUso 2018. L'intreccio dei saperi per rispettare il passato interpretare il presente salvaguardare il futuro - VI Convegno Internazionale sulla Documentazione, Conservazione e Recupero del Patrimonio Architettonico e sulla Tutela Paesaggistica. Gangemi Editore, Messina, 2437- 2442 
Di Biase, C., Casonato, C., Facchi, A., Greppi, A., 2018. Metamorphosis as ordinary process of change. Identity, Authenticity and Surviving Materials in the case study of Giuseppe Terragni's Novocomum. Metamorphosis The Continuity of Change. 15th international DOCOMOMO conference, Ljubljana, 248-253

Greppi, A., 2018. Per una storia materiale di un'icona del XX secolo: la costruzione del Novocomum di Giuseppe Terragni. In: ReUso 2018. L'intreccio dei saperi per rispettare il passato interpretare il presente salvaguardare il futuro - VI Convegno Internazionale sulla Documentazione, Conservazione e Recupero del Patrimonio Architettonico e sulla Tutela Paesaggistica. Gangemi Editore, Messina, 539-550

Napolitano, R. K., Scherer, G., Glisic, B., 2018. Virtual tours and informational modeling for conservation of cultural heritage sites. Journal of Cultural Heritage, 29, 123-129 